\title{
Knowledge-Based Assisting Tools - Real Life Inspirations
}

\author{
Jerzy POKOJSKI ${ }^{\mathrm{a}, 1}$, Konrad OLEKSIŃSKI ${ }^{\mathrm{b}}$, Jarosław PRUSZYŃSKI ${ }^{\mathrm{c}}$ and Maciej \\ MAZIK $^{\mathrm{d}}$ \\ anstitute of Machine Design Fundamentals, Warsaw University of Technology \\ ${ }^{\mathrm{b}}$ Institute of Machine Design Fundamentals, Warsaw University of Technology \\ ' Institute of Machine Design Fundamentals, Warsaw University of Technology \\ ${ }^{\mathrm{d}}$ Faculty of Automotive and Construction Machinery Engineering, Warsaw \\ University of Technology
}

\begin{abstract}
These days are characterized by globalization and digitization. The scope of both these phenomena is growing in an evolutionary manner. At the same time, knowledge resources are increasing, and in many cases specific knowledge is becoming globally available, and its representation is to a large extent differentiated, more and more efficient, and more effectively digitized. The techniques resulting from the abovementioned trends allow wider and simpler knowledge sharing, for more frequent and inspiring compilation and interaction of different sources of knowledge. Classic formal and informal methods and tools based on modelled knowledge must take into account these phenomena and processes. Due to the specific level of development of computer resources and knowledge modelling tools, a defined infrastructure of methods and tools has come into being. We define this stage of knowledge modelling as level I. The processes of creating and generating knowledge is also an interaction between various sources of knowledge: human and computer. We define this stage of knowledge modelling as level II. In addition to the approaches mentioned above, there is a group of tools that were created by artificial intelligence, e.g. case-based reasoning, machine learning, data mining, etc. We define this stage of knowledge modelling as level III. Farreaching specialization is progressing in many real-world processes. Consequently, the used tools, including computer tools, are subjected to this process. An example of such a solution can be a system which is used to support the design process of certain selected types of manufacturing machines.
\end{abstract}

Keywords. Engineering knowledge modelling, Knowledge-Based Engineering, assisting systems in engineering

\section{Introduction}

These days are characterized by globalization and digitization $[1,2]$. The scope of both these phenomena is growing in an evolutionary manner. At the same time, knowledge

1 Corresponding Author, Mail: jerzy.pokojski@pw.edu.pl. 
resources are increasing, and in many cases specific knowledge is becoming globally available. Its representation is to a large extent differentiated, more and more efficient, and more effectively digitized [3-9]. Knowledge is recorded and stored in digital knowledge repositories which are usually dedicated to specific classes of applications.

The techniques resulting from the above-mentioned trends allow wider and simpler knowledge sharing, for more frequent and inspiring compilation and interaction of different sources of knowledge. They also enable the user to return to existing resources, making them materially helpful in reflection. Knowledge in a formalized form can become the basis for expanding the possibilities of classic tools used in various professions by providing multi-variability, comprehensiveness, flexibility, and a higher level of adaptation to existing realities.

Classic formal and informal methods and tools based on modelled knowledge must take into account these phenomena and processes. There is an urgent need to create new approaches and formalisms that are able to tie classic modelling and knowledge management tools with current trends.

The construction of tools whose operation is based on knowledge often depends very strongly on the quality of the acquired knowledge, and on how deeply the captured knowledge is acquired, modelled and preserved. These elements of knowledge processing processes have the greatest impact on the quality of implemented solutions, but they are usually labour-intensive.

Due to the specific level of development of computer resources and knowledge modelling tools, a defined infrastructure of methods and tools has come into being. Here we can obtain tools for consolidating formal, informal, advisory and encyclopaedic knowledge, where knowledge is subject to detailed verification and validation. The knowledge is published in one way or another, is available online, and its representations are mainly multimedia with annotations. The evolution process of the knowledge is captured with the help of the versatility tool. We define this stage of knowledge modelling as level I $[3,4]$.

The processes of creating and generating knowledge is also an interaction between various sources of knowledge: human and computer. These are sequences of actions that take the form of associations, inferences, and reflections. Remembered or saved in a different way, they often become the source of inspiration to develop something new. For that purpose, the knowledge sources require different representations - multimedia, commented multimedia, supplemented with references, explanations, associations, which are sometimes based on ontologies, etc. In many of these activities they support the so-called assistance systems based on knowledge / information, group / personal management concepts using a variety of different methods. We define this stage of knowledge modelling as level II [3, 4].

In addition to the approaches mentioned above, there is a group of tools that were created by artificial intelligence, e.g. case-based reasoning, machine learning, data mining, etc. These tools require a certain quality standard of the processed data, which are based on certain formal representations. In this case the modelled problems can be the effect of mixing or converting the representations used in the approaches discussed above (levels I and II). There is an increasing demand for tools supporting this class of tasks, i.e. tools ensuring high quality of obtained data sets. We define this stage of knowledge modelling as level III [3, 4].

The authors of this work based their findings on an analysis of the literature in the field of methods and tools for modelling engineering design knowledge. They refer to both achievements that are treated as classic [10-14], as well as relatively new and 
innovative solutions $[1-9,15]$. They compare the above achievements with the facts that take place in realistically functioning forms, at present, in real industry. These considerations are multi-threaded and relate to facts observed at different levels of modelled reality. The paper refers to both industrial realities and modelling of real, functioning engineering knowledge.

The analysis of the functioning of knowledge-based tools in real industrial conditions cannot be reduced to the tools themselves. Design processes are also important: their characteristics, degree of innovation, level of advancement of obtained design solutions, assessment of how the tools contribute to the creation of a high level of construction. In order to provide this context, the paper presents the substantive characteristics of a specific, industrial design process implemented and supported by means of tools based on knowledge. While performing this characteristic, it is impossible not to notice the influence of a number of different, other factors on the final results obtained in the implemented design processes. These are, e.g. the level of computer resources used, the degree of preparation of designers in terms of their knowledge of computer aided design methods, and many others, considered as factors evolving over time. The visible evidence of success are the events which had a breakthrough character and a very significant impact on the structures created. The paper analyses such events and presents their components and factors. In all cases, specific knowledge, decisions and conditions were followed by specific successes to varying degrees.

The team (in a changing composition) to which the authors belong has been dealing with the subject of modelling engineering knowledge for 30 years [16-20]. The abovementioned phenomena, globalization and digitization, have also been overlapped by the attempts of the team members to implement various methods and tools based on the modelling of engineering knowledge in real industrial applications at different levels and at different periods of time. It was also a period of intensive development of engineering design knowledge, taking place both globally and at the level of individual design offices.

Due to the wide range of issues and content, as well as the time span, the authors chose case studies as a method of presenting their achievements.

\section{Case study}

The authors of this study cooperate with a company dealing with the design and construction of various types of production lines for plastic sheet metal processing [3.4]. It is a relatively small company (about 60 employees, including 12 people employed in the design office) realizing the model of unit production.

Guillotine cutting is very often used in this industry. It is a waste-free, efficient processing method, the cutting tools have a long service life, and their inspection and maintenance are relatively inexpensive.

This chapter describes the evolution of technical solutions used in the construction of cutting devices for sheet metal and profiles made of sheet metal, which have been used since the 1990 s to the present day in this company. The description also refers to the development of supporting tools used in design processes during this period. Due to the multitude and variety of types of processes and cutting equipment, the company has a lot of such equipment designed and manufactured over the years. Figure 1 shows some of the more interesting shapes for which the cutting equipment was built.

The case description consists of two parts. The initial one chronologically presents some of the key projects that had a significant impact on the directions of development 
of subsequent devices of this type. In the next part there is a reference to the design tools used, as well as a generalisation of the observed phenomena and an attempt to assign the knowledge and tools modelled there to particular levels (I, II or III level) mentioned in the introduction. A description of various external factors relevant to the project work was also added, as well as descriptions of events of significant importance. The material used for the analyses came from the sum of accounts of persons participating in engineering works.

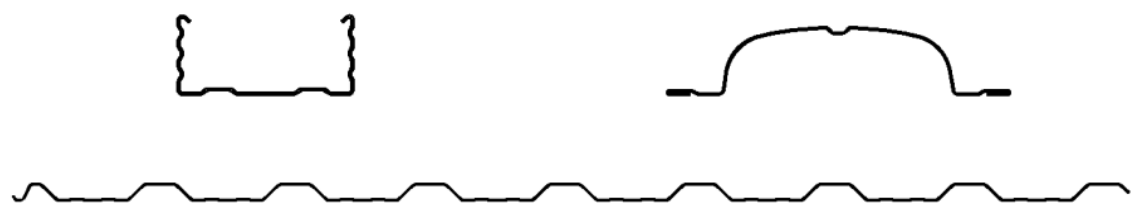

Figure 1. Sample shapes of guillotine cut details.

\section{Historical background to the development of guillotine devices - evolution of conceptual solutions}

This chapter presents the process of evolution of specific, conceptual design solutions in a historical perspective [21-24]. The beginning of the presented deliberations is the first half of the 1990s. In that period the company produced only simple hydraulic guillotines for cutting flat sheets. An outline of two types of such devices is presented in Figure 2 design case A. At this stage of development only basic calculation methods were used. Some knowledge of technological conditions was also used. At that time, the group of constructors consisted of only 2 people, and the transfer of knowledge took place through direct exchange of thoughts and the joint development of issues.

In the mid-1990s there was a need for guillotines for cutting trapezoidal sheets. In the case of trapezoidal sheets, the geometry of the cutting knives was problematic. The direct adaptation of the cutting principles (inclination of the movable knife by about 2 degrees) of flat sheets proved to be a failure. At that stage the only intuitively correct solution seemed to be to cut off this type of product "at once" without using step cutting. However, this would have resulted in a very significant increase in cutting force, so large that building such a device would not make economic sense. This forced designers to look for another solution. Finally, after many tests and trials, it was possible to develop a knife geometry that allowed good cutting quality with the required cutting force that was at an acceptable level. Figure 2 design case B gives an overview of the shape of the designed knives for trapezoidal and flat sheet metal cutting.

Another noteworthy modification of the guillotine type devices in the presented company took place in 2005 . At that time, the first ever guillotine driven by a gearbox with an electric motor (instead of a hydraulic cylinder) was designed and built. The factors that made it possible were a significant (compared to the situation in the mid1990s) drop in the prices of electric drives, as well as the significant dissemination of this technology, which resulted in the fact that the company's automation engineers were able to design and build appropriate power supply systems. Another advantage of such a solution is that it does not require servicing and maintenance, which is necessary in the case of hydraulic systems. Figure 2 design case $\mathrm{C}$ shows an illustrative sketch of the construction of the guillotine for cutting trapezoidal or flat sheets with the electric drive. 
In 2010, the company built the first profile cutting guillotine, which can be qualified as two and a half dimensions. This concept is based on the fact that the roll formed section in two dimensions was cut in a shape other than straight. Figure 2 design case D shows the construction of such a guillotine.

The next stage in the development of sheet metal cutting technology was the introduction of devices called "flying" guillotines. This is a solution that allows the cutting off of the material (in our case steel sheets and sections) without stopping the device. The main advantage of this method is a significant increase in the efficiency of the production line because time is not wasted on stopping it and starting again with each cutting cycle. The first realization of the device with this feature took place in 2011. As for the construction, a typical guillotine is mounted on a moving trolley which synchronizes its speed with the speed of the production line. During this time, the cutting takes place. Then the trolley returns to its base position and waits for the next cutting operation. The development of this technology was made possible by further increasing the competence of the automation department, purchasing new machining centres, and developing the knowledge of the design department. Figure 2 design case E shows a conventional and "flying" guillotine for cutting sheet metal.

In 2012, the company received an order to build a machine that would be able to cut corners and holes on flat sheets. In order to meet this challenge, a machine was built that used concepts previously developed for guillotines to cut flat sheets. They were developed with modules for punching out corners and holes. Quite an important innovation was to build software that was able to automatically create machine code directly from flat drawings in the *.dxf format. Figure 2 design case $\mathrm{F}$ shows this type of machine.

The development of "flying" guillotine technology has opened up the possibility of supplying machines for profile production of so-called "dry wall sections". The requirements for these machines are very high performance and high reliability. In the course of such a task (in 2015) a technology was additionally developed that allowed for waste-free cutting. Figure 2 design case $G$ shows a guillotine for cutting this type of product.

In 2018, the concept for a machine for cutting, and punching out corners and holes with the possibility of punching out similar shapes in a roll formed section was developed. Figure 2 design case $\mathrm{H}$ shows such machine.

Another challenge in 2018 was to cut, using a guillotine, a section that had vertical walls quite close together. Although its shape is similar to the shape of trapezoidal sheets, in this case it was not possible to apply the rules and knowledge of these issues due to the fact that the walls were parallel to each other, and this breaks all the rules of staged cutting (mentioned in the section above concerning trapezoidal sheet cutting). After a series of attempts, the assumed results were achieved. During these tests, new, very valuable knowledge on this type of cutting was acquired. Cutting these types of profiles is always done with saws or circular cutters. Figure 2 design case I shows the device for cutting it.

In 2019, the concept for the device discussed above was extended upon request. This time, the parallel-wall profiles were cut at an angle of 45 degrees. Figure 2 design case $\mathrm{J}$ shows this device, and also a section cut at an angle of 45 degrees.

Figure 2 shows all the issues discussed above and their position in the timeline. In the next part of the article they will be discussed in more detail in terms of the sources of knowledge used and the techniques of processing. 


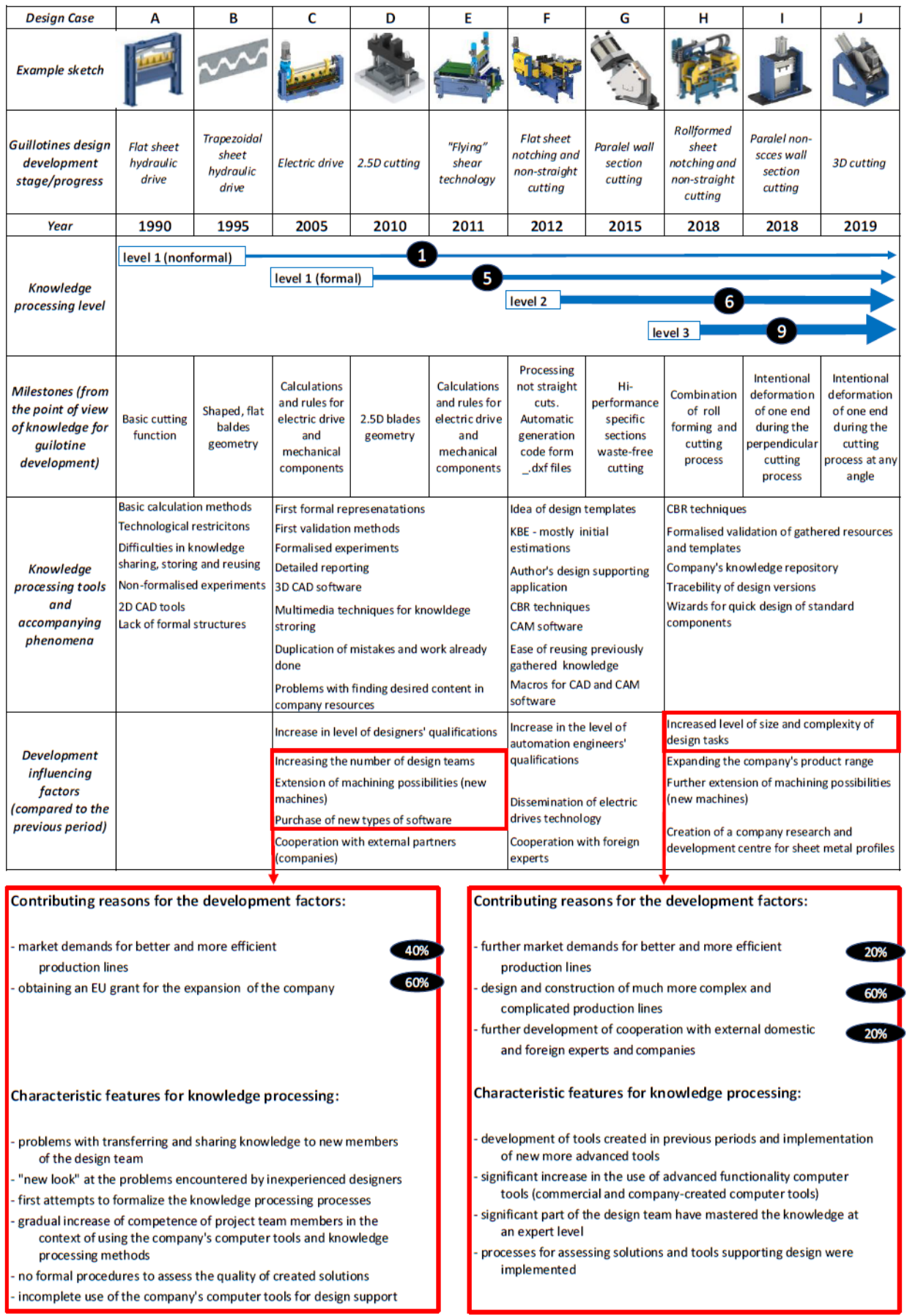

Figure 2. Evolution of metal cutting machines development. 


\section{Tools for knowledge processing and management - historical background}

The beginning of the presented deliberations is the first half of the 1990s. In that period the company produced only simple guillotines. Due to this, as well as the small size of the design team, only informal procedures and calculation methods related to them functioned then. Often, not entirely rational reasons for design decisions were taken into account. The main and, in principle, the only source of knowledge, was the design documentation and quite sporadic records of the calculations carried out. Despite the fact that the team of designers at that time consisted of up to three people, there were significant difficulties in sharing knowledge. The phenomenon of pointless and thoughtless duplication of some activities could be observed. There was also a lack of evaluation of newly designed solutions, which in consequence led to the creation of new solutions containing the same errors that occurred in earlier implementations. In the available resources it was usually impossible to find the premises that were behind the choice of specific solutions, which of course made the process of reuse, or use with changes of one of the old solutions much more difficult. Despite the lack of any formal structures, knowledge was partly preserved, partly verified and partly validated. However, these activities were usually carried out only mentally, separately by each of the designers. Taking this into account, the activities and methods from that period can be qualified as non-formalised level I tools.

This state of affairs lasted until the second half of the 2000-2010 period. One of the factors leading to change was that new people with relatively little professional experience joined the team during this period. Due to the fact that the knowledge resources were in no way formalised, the implementation of new employees to work in the team was very slow and hard. This fact highlighted the need to consolidate and manage certain knowledge resources. Initially, these were primarily resources containing formal, textbook knowledge, which were made available online. Over time, the system was developed with very simple validation tools. These were extensive collections of notes, films and photographs where both problems and their solutions that occurred during the manufacture, assembly, commissioning or operation of a given device were recorded. These activities were of a bottom-up nature. In the initial phase they were not fully implemented in a planned and conscious manner. From today's perspective it is also group I.

The next step is already targeted actions from 2012 [3, 4]. At this stage, some of the processes were already formalised. Many times, it was possible to use them or their parts for activities other than those for which they were created. A concept of templates was created, which conceptually was related to specific classes of project activities. This formalism was intensively developed towards integrating both informal and formal representations into a single template. Appropriate classes for each of these two cases have been identified. The versionality of the templates was introduced, as well as the monitoring of their use cases and planned future use cases. Elements of investment policy were added in this area. Each of the above-mentioned variants could be created as an effect of real engineering processes. It could also be an effect of the reflection of individual designers or the discussions of several designers. All these elements were properly recorded and commented on. These solutions represent level II.

Around 2015, experiments with CBR (Case Based Reasoning) class solutions were initiated $[17,18]$. It was primarily that in levels I and II a fairly large set of different representations was used. It became necessary to create level III so that a uniform representation could be applied to the CBR method. Figure 2 presents the development 
of cutting equipment design with the assignment of their subsequent stages to specific classes of knowledge modelling tools.

Another element was various efficiency solutions related to the use of $\mathrm{CAD} / \mathrm{CAE}$ systems. Far-reaching specialization is progressing in many real-world processes. Consequently, the used tools, including computer tools, are subjected to this process. CAD / CAE class systems may turn out not to be often needed in their entirety; only some of their functions are needed, almost in the form of a dedicated service. The way engineers/designers define a problem is also changing - a more advanced division into human-defined components (expressing his ideas - creative actions) and automatically implemented components that are easy for a computer to interpret and proceed is possible.

An example of such a solution [25] can be a system which is used to support the frame design process of certain selected types of machines. Defining the structure and parameters of the frame is done by the designer using the $3 \mathrm{D}$ wire modelling editor. Next, the obtained model is supplemented, also by the designer, with icons that define the cross-section forms and connections of individual frame elements. Then the basic information, necessary to build FEM models of this frame, is entered (which is done by the designer). Further processing is already a typical automation. It involves the automatic construction of a detailed geometric model with the use of a CAD system, the automatic construction of the FEM model, and finally the automatically controlled analysis of this model. Work with this application resembles the cooperation between a designer and an assistant, where the human defines the basic components of the design task. Of course, the designer usually has more such highly specialized tools at hand.

In addition, the analysed processes widely took into account other elements, apart from the substantive side of design processes and knowledge-based support tools. The main factors are presented in Figure 2. In addition, the same picture shows two selected events, crucial for the functioning of the company, with their background in terms of knowledge, decisions and other elements. In the picture, each event is linked by lines to specific elements affecting it. The degree of importance of this influence for the whole event is shown by a dimensionless indicator from the range 1-10 (10 - maximum influence). The values of this indicator are the averaged values given by persons reporting on the studied processes.

\section{Conclusions}

In conclusion, we can say that the use of knowledge-based tools in product design and development processes has several contexts of tools based on different representation levels of the modelled knowledge (levels I, II, III) [3, 4, 26, 27]. An equally important context is the dedicated KBE tool. All of these 4 elements (three levels and the KBE tool) constitute a whole system connected with many dynamic relations. For example, knowledge acquired and stored at levels I and II becomes the basis for building dedicated $\mathrm{KBE}$ tools. Experience in using KBE tools becomes the basis for articulating knowledge at levels I and II, etc.

An equally important issue, in the case of the analysis of real project tasks, is the substantive side of the project, the level of its complexity, and the whole set of various additional factors, the impact of which is crucial for the functioning of the whole. The analysis made by the authors, fragments of which are included in the paper, has shown that the success of methods supporting knowledge-based design is determined by quite 
a number of elements that occur in the so-called broader context of the analysed engineering processes $[15,18,24,30]$.

The created whole provides not only the possibility of short-term management of engineering knowledge, but also, in the long run, allows for the analysis of the evolution process of design methods used in a given company [22]. This may constitute a basis for the application of approaches of a more strategic dimension.

The adopted solutions also assume a very important personal/team aspect of the modelled engineering knowledge [3, 4, 18, 28, 29, 30].

\section{References}

[1] J. Stjepandic, N. Wognum, W.J.C. Verhagen, Concurrent Engineering in the 21st Century: Foundations, Developments and Challenges, Springer, Cham, 2015.

[2] S.K. Chandrasegaran, K. Ramani, R.D. Sriram, I. Horváth, A. Bernar, R. F. Harik, W. Ga, The evolution, challenges, and future of knowledge representation in product design systems, Computer-Aided Design, 2013, Vol. 45, pp. 204-228.

[3] J. Pokojski, K. Oleksiński, J. Pruszyński, Knowledge based processes in the context of conceptual design, Journal of Industrial Information Integration, 2019, Vol. 15, pp. 219-238.

[4] J. Pokojski, K. Oleksiński, J. Pruszyński, Conceptual and Detailed Design Knowledge Management in Customized Production - Industrial Perspective, Journal of Computational Design and Engineering, Volume 6, Issue 4, October 2019, pp. 479-506.

[5] L.F. Sikos, Description Logics in Multimedia Reasoning, Chapter 5 Multimedia Ontology Engineering (C) Springer International Publishing AG, Cham, 2017.

[6] B. He and P. Feng, Research on collaborative conceptual design based on distributed knowledge resource, International Journal of Advanced Manufacturing Technology, Vol. 66, 2013, pp. 645-662.

[7] A. Fraga, J. Llorens, L. Alonso, and J. M. Fuentes, Ontology-Assisted Systems Engineering Process with Focus in the Requirements Engineering Process, In: F. Boulanger et al. (eds.), Complex Systems Design \& Management, (C) Springer International Publishing Switzerland, 2015, pp. 149-161.

[8] M. Kaufmann, A. Waldis, P. Siegfried, G. Wilke, E. Portmann, M. Hemmje, Intuitive Knowledge Connectivity: Design and Prototyping of Cross-Platform Knowledge Networks, In: F. Lehner and N. Fteimi (Eds.): KSEM 2016, LNAI 9983, 2016, pp. 337-348.

[9] J. Johansson and F. Elgh, Applying Connectivism to Engineering Knowledge to Support the Automated Business, Advances in Transdisciplinary Engineering, Vol. 5, 2017, pp. 621-628.

[10] R. Sriram, Intelligent Systems for Engineering. A Knowledge Based Approach, Springer-Verlag, London, 1997.

[11] R.D. Sriram, Distributed and Integrated Collaborative Engineering Design, Sarven Publishers, Glenwood, 2002.

[12] Ch. Tong, D Sriram, (Ed), Artificial Intelligence in Engineering Design, Volume 1, 2, 3, Academic Press, Oxford, 1992.

[13] S. Szykman, R.D. Sriram, Ch. Bochenek, J.W. Racz, J. Senfaute J., Design Repositories: Engineering Design's New Knowledge Base. IEEE Intelligent Systems, May/June, 2000, pp. 48-54.

[14] J. Clarkson ,C. Eckert (ed.), Design Process Improvement. A revive of current practice. Springer-Verlag, London 2005.

[15] D. Monticolo, J. Badin, S. Gomes, E. Bonjour, D. Chamoret, A meta-model for knowledge configuration management to support collaborative engineering, Computers in Industry, 2015, Vol. 66, pp. 11-20.

[16] J. Pokojski (ed.), Intelligent Support of CAE Environment Integration in Machine Design, WNT, Warszawa, 2000, (In Polish).

[17] J. Pokojski (ed.), Case Based Reasoning Application in Machine Design, WNT, Warszawa, 2003. (In Polish)

[18] J. Pokojski, IPA (Intelligent Personal Assistant) - Concepts and Applications in Engineering, SpringerVerlag, London, 2004.

[19] J. Pokojski, Expert Systems in Machine Design, WNT, Warszawa, 2005. (In Polish)

[20] G. Linkiewicz, W. Marowski, J. Pokojski (eds.), Computer Aided Design in Distributed Environment, WNT, 2007. (In Polish)

[21] G. Pahl, W. Beitz, and al., Engineering Design: A Systematic Approach, Springer-Verlag, New York, 2007.

[22] W.B. Arthur, The Nature of Technology, FREE PRESS, New York, 2009 
[23] D.G. Ullman, The Mechanical Design Process, McGraw-Hill (Third Edition), New York, 2002.

[24] M. M. Andreasen, C. T. Hansen, P. Cash, Conceptual Design, Interpretations, Mindset and Models, Springer International Publishing, Switzerland 2015.

[25] M. Mazik, KBE Support of 3D Frame Conceptual Modelling, Diploma, Institute of Machine Design Fundamentals, Warsaw University of Technology, 2019.

[26] J. Pokojski, M. Gil, M., K. Szustakiewicz, Engineering Knowledge Modelling in Design. In Jerzy Pokojski, Shuichi Fukuda, Józef Salwiński (eds.): New World Situation: New Directions in Concurrent Engineering, Proceedings of the 17th ISPE International Conference on Concurrent Engineering (Advanced Concurrent Engineering), Springer-Verlag, 2010, pp. 257-266.

[27] J. Pokojski, K. Szustakiewicz, Extended KBE - Scenario of an Application Development. In J. Stjepandic, G. Rock, C. Bil (eds.): Concurrent Engineering Approaches for Sustainable Product Development in a Multi_Disciplinary Environment. Proceedings of the 19th International Conference on Concurrent Engineering, Springer, 2012, pp. 291-302.

[28] G.E. Gorman, D.J. Pauleen, The Nature and Value of Personal Knowledge Management, in: D. Pauleen \& G. Gorman (eds.) Personal Knowledge Management: Individual, Organizational and Social Perspectives, Gower:London, 2010, pp. 1-16.

[29] M. Völkel, Personal Knowledge Models with Semantic Technologies, Books on Demand GmbH, Norderstedt, 2010.

[30] J. Schmidt, M. Borsato, E. Hinckel, P. Storrer, E. Onofre and F. Maccari, A framework for capturing and applying design knowledge in new product development, International Journal of Agile Systems and Management, 2018, Vol. 11, No. 1, pp. 23-40. 